\title{
The Role of Integrated Marketing Communications in Enhancement of SMEs Growth in South Africa
}

\author{
Lawrence Mpele LEKHANYA, \\ Durban University of Technology, South Africa \\ lawrencel@dut.ac.za
}

\begin{abstract}
The intention of this paper is to discover and empirically test the knowledge gap exist with regard to the role that integrated marketing communication (IMC) plays in the enhancement of SMEs growth. A quantitative approach is followed in this paper, with a questionnaire as the research instrument and questionnaire items established through a literature review. A sample of 374 SMEs owners/managers agreed to complete the questionnaire. In order to give a descriptive overview of variables relevant to the objectives of the study, a Cronbach test was performed. Certain ability in marketing communication by SMEs was evident from the sample. However, very few marketing communication tools are fully applied in order to enhance SMEs growth. A significant starting point, in attaching importance to the role of IMC enhancement of SMEs growth, is constituted by this paper's sample, even though it is restrictively small. Practitioners may, from this paper, understand where intervention guidelines are needed, in order to improve an IMC plan needed for SMEs. Compared to previous research done on large company practices, this paper represents an original trial to empirically apply the marketing communication approach within SMEs.
\end{abstract}

Keywords: Enhancement, Role, SMEs, Integrated, Growth, Communication, Marketing

\section{Introduction}

According to Polyorat (2014), integrated marketing communication (IMC) is considered an attempt to integrate and synthesize its promotional mix, which includes advertising, sales promotion, public relations, personal selling, and event and direct marketing. Many authors, such as Keller (2001), stress that marketing communications denote the means through which companies can initiate an interchange with customers and other stakeholders about various company issues, including their products and service offerings. Saeed, Naeem, Bilal \& Naz (2013) point out that IMC correlates with some positive results, such as customer satisfaction, greater profitability, increased sales and cost savings, as well as brand loyalty and awareness, positive brand image, and unique brand association. It has nonetheless been indicated that the measuring of the effectiveness of a communication mix is neglected, along with analysis of the effect of using a specific marketing communication activity on different business performance determinants (Mumel, Hocevar \& Snoj (2007). Compared to 50, 30 or perhaps even as few as 10 years ago, the marketing communications environment has changed considerably from what it was, according to Keller (2009), who attributes this to fundamental changes in the way the world communicates and interrelates, brought about by new, emerging technology. Keller (2010) holds that marketers must understand what various marketing communication options have to offer and how to best combine these to optimize their marketing communication programs.

Problem Statement: Previous South African research has uncovered that all elements of integrated marketing communications are not utilised by all small retailers (Mapheto, Oni \& Matiza, 2014; Lekhanya \& Mason, 2014). Eposito (2013) supports the assertion of limited empirical studies with a specific focus on IMC, within the milieu of small business. Often, the most dominant problem encountered by small business operators is that of sales and marketing, however, Haung \& Brown (1999) state it has, nevertheless, been acknowledged as the most important of all business activities and is vital for small businesses survival and growth. Tsikirayi, Muchenje \& Katsidzira (2012) emphasise the frequent lack of proper planning by rural SMEs, in promoting their products and services.

Aim of the Study: The study intends to examine the influence of integrated marketing communications in the enhancement of SME growth in South Africa, and to what extent this affects SME growth, and what is recommended. 


\section{The Objectives:}

- To identify and analyse which are the most integrated marketing communications tools that are efficient and which effect activities in enhancement of SME growth.

- To examine the extent to which the effectiveness of IMC tools affect SME growth.

\section{Literature Review}

Definition of marketing communication: IMC is defined by Schultz (1993) as a view of marketing communication planning that combines and evaluates the strategic role of different communication disciplines to gain clarity, uniformity and greater impact. On the other hand, Gabrielli \& Balboni (2010) explain that marketing communication has been deemed a process of systematic coordination of a company's multiple messages and many communications activities, integrating these into an unvarying marketing communications mix, to convey a clear message about itself and what it offers, to its target market. According to Kanibira, Saydanb \& Nartc (2014), marketing communication entails the processes of creating communication opportunities and sending messages to and receiving messages from consumers, in order to create the desired reactions in the target audience. Regarding the role of marketing communication mix in SMEs growth, Duncan \& Moriarty (1998) indicate that the recent concept of IMC can be described as a viewpoint that places emphasis on bringing together all the marketing mix variables and combining their programs and activities. SME owners/managers in some countries, such as Slovenia, are aware of the importance of marketing communications as the viable resource of their business performance (Snoj et al, 2001, in Mumel, Hocevar \& Snoji, 2007). Keller (2009) specifies that, to establish the required understanding, familiarity and image in consumers' minds, IMC necessitates combining and matching different communication options. According to Kanibira, Saydanb \& Nartc (2014), the aims of marketing communication are generally to support sales, to create product and brand awareness, to develop and corporate image and to shape the attitudes and behaviours of the target audience. This emphasis is maintained further by Kotler \& Keller (2012), who state that it is through marketing communications that firms attempt to, directly or indirectly, inform, persuade and remind consumers, regarding the products and brands that they sell.

Factors influencing the IMC in SMEs success growth: As pointed by Schultz (1993) that infrastructure, staffing, marketing budget and skills are some of various factors influencing the IMC in the SMEs sector. This means that not only combination of promotional mix which makes complete IMC but infrastructure of business should support. Kitchen, Brignell, Li, \& Jones (2004) state that, IMC in SMEs are greatly influenced by marketing development, the investment essential to business, and the nature of business. Types of products, as well as the nature of the market are maintained by Vargas (2005), along with price, the stage in product life-cycle and funds available for the promotion, to have a major influence in IMC of SMEs.

Integrated marketing communication and SMEs performance: The literature review has indicated that poor management skills, such as human resources, financial and general management, as well as marketing, result in the poor implementation and performance of SMEs in the sector, with regards to profitability (Mpofu \& Chigwende, 2013). In terms of the different kinds of marketing they practice, Copley (2011) indicates that SMEs are engaging with the IMC concept differently from that of bigger businesses with more resources, particularly those with entrepreneurial principals. Marketing communications activities are believed by authors, such as White (1999), to play an important role in the building and maintenance of strong brands.

Barriers to integrated marketing communication in SMEs sector: Although IMC is regarded as an important strategy for business growth there are also many obstacles in the implementing thereof (Saeed, Naeem, Bilal \& Naz, 2013). SMEs in the sector do not, according to Mpofu \& Chigwende (2013), have marketing plans due to the lack of required resources, and are not implemented by the few that have them, resulting in these organizations running trial and error strategies. Luxton, Hodge \& Reid (2002) echo the sentiment that the challenges faced by SME's intensify the difficulty of managing marketing communications, particularly where resource constraints and lack of marketing expertise are concerned. Longenecker, Moore \& Petty (2006) identify being affected by limited financial resources, as one of the aspects that characterise marketing communication in SMEs. Thrassou \& Vrontis (2006) further include lack of time and scare marketing communication skills in the fact that communication management is often part and parcel of the enterprise owner's usual concern with business and profits in general, instead of communication's impact on the market. 
Measuring the Effectiveness of integrated marketing communication of SMEs: It is held by Koekemoer \& Bird (2004) that marketing communication is comprised of the collective activities, materials and media a marketer makes use of, to inform and attempt to persuade prospective customers to purchase or use a particular offering. However, IMC is also regarded as a successive strategy that effectively provides information, creates awareness, and changes attitude, while enforcing brand loyalty, as well as building company image (Potluri, 2008). Although many authors, such as Smith \& Zook (2012) have advocated more about IMC, research and case studies are often based on large companies (Gabrielle \&Balboni, 2010). The literature shows SMEs do not necessarily use IMC channels at all (Luxton, Hodge \& Reid, 2002).

\section{Methodology}

A theoretical review of the IMC mix was done, identifying factors that influence the use of and barriers to IMC, along with its effectiveness, while identified variables were used to formulate a questionnaire.

Questionnaire: A questionnaire, compiled mainly of closed-ended questions that were identified and drawn from the literature review, was used as the main measuring instrument. SME owners/managers were asked to indicate, from a 5-point likert scale questionnaire, which of the identified variables affect their use of IMC, in order to realise business growth.

Data collection: Research assistants were recruited from the selected areas and trained as fieldworkers to administer the questionnaires at the respondents' business premises during the week and on weekends. Due to a suitable sampling frame not being available from which to draw a probability sample, the distribution and collection of self-completed questionnaires was done via a quota plan.

Table 1: Key Questions - Summary

\begin{tabular}{ll}
\hline Area of Research & Questions \\
\hline Types of IMC tools & $\begin{array}{l}\text { Which of the following types of integrated marketing communications } \\
\text { tools are used in your business? } \\
\text { Response alternative: Local advertising; Special offer; Brochures; }\end{array}$ \\
$\begin{array}{l}\text { Personal selling. } \\
\text { Factors influencing IMC use }\end{array}$ & $\begin{array}{l}\text { Which of the following factors influence the use of an integrated marking } \\
\text { communications mix in your business? }\end{array}$ \\
Response alternative: Competition; Economic; Technology; Limited funds. \\
Skills and knowledge for IMC & $\begin{array}{l}\text { Which kind of skills seem to be most required by your business? } \\
\text { Response alternative: Lack of knowledge \& experience; Never thought } \\
\text { about IMC marketing; No reason to use IMC }\end{array}$ \\
\hline
\end{tabular}

Analysis of results: Finalised questionnaires were checked for complete and missing information, after which data were captured, by means of SPSS, version 16.0. The initial analysis entailed frequencies that were also used to check the coding of data. Following this, variables were screened, singling out those of significance to the dependent variables of the study, with descriptive statistics illustrating and comparing the collected data Cross-tabulations, with the appropriate inferential statistics ( $\mathrm{Z}$ test), were used to test relationships.

Validity and Reliability: In order to assess content and construct validity, a thorough comparison of the questionnaire with the research objectives was done, in addition to it being pre-tested with a small sample that was similar to the population. No significant changes were needed. Cronbach's coefficient alpha was used to test reliability, with reliability confirmed at a coefficient of 0.773 , confirming the reliability of the study as acceptable.

\section{Findings}

Table 2: IMC - Tools used to influence growth

\begin{tabular}{lccc}
\hline Local advertising & 214 & 57 & 0.006 \\
Special offers & 159 & 45 & 0.004 \\
Brochures & 157 & 42 & 0.002 \\
Personal selling & 149 & 40 & 0.000 \\
\hline
\end{tabular}


The findings in Table 2 indicate that local advertising is preferred by 214 of the respondents ( 57 percent), while special offers were favoured by 159 (45 percent). These tools were highlighted by a large number of the respondents as the IMC tools most used by SMEs, which might explain the increase of their popularity and growth. They were followed by brochures, indicated by 157 of the respondents (42 percent) and personal selling by 149 ( 40 percent).

Table 3: Main factors affecting growth- IMC

\begin{tabular}{llll}
\hline Competition & 278 & 75 & 0.000 \\
Economic & 279 & 75 & 0.000 \\
Technology & 43 & 12 & 0.000 \\
Limited funds & 132 & 33 & 0.000 \\
\hline
\end{tabular}

Table 3 reflects the relationship between SME growth and environmental factors that affect the use of IMC, as identified through cross tabulation and Z tests. Economic was considered by 279 respondents $(75$ percent) and competition by 278 respondents ( 75 percent) as the most influential factors affecting the use of IMC in support of SME growth. The next most important factor was limited funds, indicated by 132 respondents (33 percent), followed by technology, with 43 respondents (12 percent) indicating these as the most influential factors affecting the use of IMC, in support of SME growth. A Chi-square goodness of fit test showed all variables to be significant at $\left(\mathrm{P}=.000^{*}\right)$.

Table 4: Skills knowledge - IMC

\begin{tabular}{llll}
\hline Lack of knowledge \& experience & 251 & 67 & 0.000 \\
Never thought about IMC & 353 & 94 & 0.000 \\
No reason to use IMC & 351 & 93 & 0.000 \\
\hline
\end{tabular}

Table 4 illustrates the relationship between SMEs and IMC skills and knowledge possessed by participants, as identified by means of cross tabulation and $\mathrm{Z}$ tests. The lack of knowledge and experience of IMC was indicated by 251 (67 percent) respondents as the problem most frequently experienced, as cited by the respondents, which fits when considering that they also indicated lack of funding for their businesses. However, a large number of the sample never thought about IMC, indicated by 353 (94 percent) respondents, with 351 (93 percent) respondents indicating that they do not understand why they should use IMC. A chi-square goodness of fit test was conducted and found to be significant at $\left(\mathrm{P}=.000^{*}\right)$.

Table 5: Cross-tabulation

\begin{tabular}{|r|r|r|r|r|r|r|r|r|r|}
\hline \multicolumn{2}{|c|}{$\begin{array}{c}\text { Strongly } \\
\text { disagree }\end{array}$} & \multicolumn{2}{c|}{ Disagree } & \multicolumn{2}{c|}{ Neutral } & \multicolumn{2}{c|}{ Agree } & \multicolumn{2}{c|}{ Strongly agree } \\
\hline \multicolumn{1}{|r|}{$\%$} & \multicolumn{1}{c|}{$\%$} & $\mathrm{n}$ & \multicolumn{1}{c|}{$\%$} & $\mathrm{n}$ & \multicolumn{1}{c|}{$\%$} & $\mathrm{~N}$ & $\%$ & $\mathrm{n}$ & \multicolumn{1}{c|}{$\%$} \\
\hline 68 & $18.2 \%$ & 44 & $11.8 \%$ & 80 & $21.4 \%$ & 151 & $40.4 \%$ & 31 & $8.3 \%$ \\
7 & $1.9 \%$ & 43 & $11.5 \%$ & 135 & $36.1 \%$ & 104 & $27.8 \%$ & 85 & $22.7 \%$ \\
7 & $1.9 \%$ & 18 & $4.8 \%$ & 70 & $18.7 \%$ & 137 & $36.6 \%$ & 142 & $38.0 \%$ \\
8 & $2.1 \%$ & 24 & $6.4 \%$ & 84 & $22.5 \%$ & 141 & $37.7 \%$ & 117 & $31.3 \%$ \\
7 & $1.9 \%$ & 29 & $7.8 \%$ & 60 & $16.0 \%$ & 135 & $36.1 \%$ & 143 & $38.2 \%$ \\
11 & $2.9 \%$ & 23 & $6.1 \%$ & 53 & $14.2 \%$ & 114 & $30.5 \%$ & 173 & $46.3 \%$ \\
16 & $4.3 \%$ & 27 & $7.3 \%$ & 44 & $11.8 \%$ & 127 & $34.1 \%$ & 158 & $42.5 \% \mid$ \\
\hline
\end{tabular}

A likert scale questionnaire was used to find the respondents who agree and disagree that IMC is very important to the growth and popularity of their businesses. The results, shown in the cross-tabulation set out in Table 5, indicate a large number of the respondents agreeing that IMC tools play a major role in their business growth enhancement.

Limitations: A number of limitations applied to this study, which means that generalization of results should be done with care. The limitations include the size of the sample being small and that it was limited to the registered businesses in only one province, KwaZulu-Natal. In addition, the study used a structured questionnaire, limiting respondents to the chosen factors, even though in some cases, respondents wanted to discuss other issues and constraints. 
Managerial Implications: Some useful understanding is provided by the study of the IMC mix, factors influencing its use, and barriers to the use of the IMC mix, as well as the effectiveness of IMC of SMEs and how these all affect SME growth. In general, SMEs owners/mangers should improve their marketing skills and knowledge, with specific reference to the application of marketing promotional tools and their benefits on SMEs' business growth. The study indicates that a broad understanding of various factors that influence their business performance will aid SMEs to identify proper marketing strategies for their businesses locations.

\section{Conclusion}

This study attempted to establish an understanding of IMC that influences SME growth, as well as identifying the most significant factors that affect the use of IMC for SME growth. It has been found that the most promotional tools used were local advertising and special offers, while limited funding has been indicated as a major factor affecting the use of IMC in the SME sector, resulting in SME owners/managers' failure to hire/employ skilled people. It was also found that lack of skills and knowledge, with regard to marketing strategies, makes it difficult for SMEs to apply all IMC tools to enhance popularity and growth.

Recommendations: It is recommended, based on the results of the study that entrepreneurial marketing education should be a priority in ensuring that management or owner/managers understand both what IMC is, as well as its importance. A deliberate programme of training and development for management of SMEs is therefore vital. Although the ministry of SMEs and the Department of Trade and Industry offer these courses, they should be made more accessible to those SMEs without financial resources. On the other hand, SME owners/managers should, however ensure the training of employees who handle marketing issues for the organization. Furthermore, the Government should, via the Ministry of Small Enterprises, assist by arranging regular marketing workshops and seminars. An additional recommendation is that SMEs employ management with the proper know-how and skills to execute the company's marketing communications mix. Since market requirements, are always dynamic, SMEs should be able to adjust to these and be sufficiently flexible to change operational strategies, in relation to market place changes. Moreover, SMEs should seek out the services of professional business consultants, advertising agents and experienced marketing personnel, in order to ensure proper planning, resource allocation and on how best to apply and carry out the marketing communications mix. This can be achieved by drawing on the resources allocated to marketing activities, to pay for outsourced marketing communications.

Recommendations for further research: The intention of this study is to establish a basis for IMC knowledge and marketing professionalism, within SMEs in the South African context. Further studies should be encouraged on the benefits of a suitable IMC approach in South African organizations, as this has the potential to increase profits and ensure SMEs' long-term sustainability. Based on the findings of this study, further research could explore SME owners/managers' attitudes towards IMC.

\section{References}

Duncan, T. \& Moriarty, S. E. (1998). A communication-based marketing model for managing relationships. Journal of Marketing, 62(2), 1-13.

Copley, P. (2011). Integrated Marketing Communications (IMC) is not just for the big boys part of the future of IMC lies in SME marketing strategy [Online]. Available at: http://www.isbe.org.uk/Copley11 (Accessed 11/02/2015).

Esposito, A. (2013). Insights about integrated marketing communication in small-and-medium-sized Italian enterprises. Business Systems Review, 2(1), 80-98.

Haung, X. \& Brown, A. (1999). An analysis and classifications of problems in small business. International Small Business Journal, 18(1), 75-85.

Kanibira, H., Saydanb, R. \& Nartc, S. (2014). Determining the Antecedents of Marketing Competencies of SMEs for International Market Performance, 10th International Strategic Management Conference. Procedia - Social and Behavioral Sciences, 150, 12 - 23.

Keller, L. (2010). Mastering the marketing communications mix: micro and macro perspectives on integrated marketing. Journal of Marketing Management, 17, 7-8.

Keller, K. L. (2009). Building strong brands in a modern marketing communications environment. Journal of Marketing Communications, 15, 139-155. 
Keller, K. L. (2001). Mastering the marketing communications mix: micro and macro perspective on integrated marketing communication programs, Journal of Marketing Management, 17, 819-47.

Kitchen, P. J., Brignell, J., Li, T. \& Jones, G. S. (2004). The emergence of IMC: a theoretical perspective. Journal of Advertising Research, 44(1), 19-30.

Koekemoer, L. \& Bird, S. 2004. Marketing Communications. Juta and Company Limited.

Kotler, P. \& Keller, K. (2012). Marketing management $4^{\text {th }}$ edition, Pearson education.

Gabrielli, V. \& Balboni, B. (2010). SME practice towards integrated marketing Communications. Marketing Intelligence \& Planning, 28(3), 275-290.

Lekhanya, L. M. \& Roger, B. M. (2014). Selected key external factors influencing the success of rural small and medium enterprises in South Africa. Journal of enterprises culture, 22(3).

Longenecker, J. G., Moore, C. W. \& Petty, J. W. (2006). Small Business Management: An Entrepreneurial Emphasis. Mason, OH: International Edition, Thomson/South Western.

Luxton, S., Hodge, C. \& Reid, M. (2002). Examining the Relevance of IMC in the Australian SME Context [Online]. Available at: http://anzmac.org/conference_archive/2002/papers/pdfs/ p200_luxton.pdft, (Accessed 11/02/2015).

Mapheto, L. M., Oni, O. A. \& Matza, T. (2014). The Utilisation of Integrated Marketing Communication Strategies by Small Retailers in Mankweng, South Africa. Mediterranean Journal of Social Sciences, MCSER Publishing, Rome-Italy, 5(15), 111.

Mumel, D., Hocevar, N. \& Snoji, B. (2007). How Marketing Communications Correlates With Business Performance. Journal of Applied Business Research - Second Quarter, 23(2).

Thrassou, A. \& Vrontis, D. (2006). A small services firm marketing communications model SME dominated environments. Journal of Marketing Communications, 12(4), 183-202.

Mpofu, T. \& Chigwende, S. (2013). Factors Influencing Marketing Planning and Implementation in Zimbabwean SMEs. International Journal of Sciences: Basic and Applied Research (IJSBAR), 12(1), 82-92.

Polyorat, K. (2014). Integrated marketing communication for SME's organic fertilizer: the case study of Men-ngern. [Online]. Available at: http://www.lcbronline.com/index_files/proceedingsemc12/ 12emc004.pdf. (Accessed 29/01/2015).

Potluri, R. M. (2008). Assessment of Effectiveness of Marketing Communication Mix Elements in Ethiopian Service Sector. Journal of Business Management, 2(3), 59-64.

Saeed, R., Naeem, B., Bilal, M. \& Naz, U. (2013). Integrated Marketing Communication: A Review Paper. Interdisciplinary Journal of Contemporary Research in Business, 5(5), 124

Schultz, D. E. (1993). Integrated Marketing Communications: Maybe Definition is in the Point of View, Marketing News.

Smith, P. R. \& Zook, Z. (2012). Marketing Communications: Integrating Offline and Online with Social Media, fifth edition, London: Kogan Page.

Vargas, R. D. (2005). Integrated Marketing Communications-an Effective, Comprehensive. [Online]. Available at: http://www.fairfaxcountyeda.org/sites/default/files/publications/bv4q05_0.pdf (Accessed 28/04/2015).

White, R. (1999). What can advertising really do for brands? International Journal of Advertising, 18 (1), 3 $-22$.

Tsikirayi, M. C. R., Muchenje, B. \& Katsidzira, Z. (2012). Impact of integrated marketing communications mix (IMCM) in small to medium enterprises (SMEs) in Zimbabwe as a marketing tool. Research in Business and Economics Journal. [Online]. Available at: http://www.aabri.com/manuscripts/121362.pdf (Accessed 28/04/2015). 